University of Nebraska - Lincoln

DigitalCommons@University of Nebraska - Lincoln

USDA Wildlife Services - Staff Publications

U.S. Department of Agriculture: Animal and Plant Health Inspection Service

2013

\title{
Multidisciplinary Approach to Epizootiology and Pathogenesis of Bat Rabies Viruses in the United States
}

\author{
J. A. Ellison \\ Centers for Disease Control and Prevention \\ S. R. Johnson \\ United States Department of Agriculture \\ N. Kuzmina \\ Centers for Disease Control and Prevention
}

A. T. Gilbert

Centers for Disease Control and Prevention, Amy.T.Gilbert@aphis.usda.gov

W. C. Carson

Centers for Disease Control and Prevention

See next page for additional authors

Follow this and additional works at: https://digitalcommons.unl.edu/icwdm_usdanwrc

Ellison, J. A.; Johnson, S. R.; Kuzmina, N.; Gilbert, A. T.; Carson, W. C.; Vercauteren, Kurt C.; and Rupprecht, C. E., "Multidisciplinary Approach to Epizootiology and Pathogenesis of Bat Rabies Viruses in the United States" (2013). USDA Wildlife Services - Staff Publications. 1127.

https://digitalcommons.unl.edu/icwdm_usdanwrc/1127

This Article is brought to you for free and open access by the U.S. Department of Agriculture: Animal and Plant Health Inspection Service at DigitalCommons@University of Nebraska - Lincoln. It has been accepted for inclusion in USDA Wildlife Services - Staff Publications by an authorized administrator of DigitalCommons@University of Nebraska - Lincoln. 


\section{Authors}

J. A. Ellison, S. R. Johnson, N. Kuzmina, A. T. Gilbert, W. C. Carson, Kurt C. Vercauteren, and C. E. Rupprecht 
SPECIAL ISSUE - BATS

\title{
Multidisciplinary Approach to Epizootiology and Pathogenesis of Bat Rabies Viruses in the United States
}

\author{
J. A. Ellison ${ }^{1}$, S. R. Johnson ${ }^{2}$, N. Kuzmina ${ }^{1}$, A. Gilbert ${ }^{1}$, W. C. Carson ${ }^{1}$, K. C. VerCauteren ${ }^{2}$ and \\ C. E. Rupprecht ${ }^{1}$ \\ ${ }^{1}$ Division of High-Consequence Pathogens and Pathology, Centers for Disease Control and Prevention, Atlanta, GA, USA \\ 2 United States Department of Agriculture, National Wildlife Research Center, Fort Collins, CO, USA
}

\section{Impacts}

- In North America, the greatest diversity of rabies viruses is found within the Order Chiroptera and new rabies viruses are being described regularly.

- Bats infected with rabies viruses display diverse clinical signs, and the use of infrared thermography may be useful in predicting onset of disease in animals infected with lyssaviruses and other agents.

- Enhanced surveillance using thermographic techniques under field conditions could provide greater utility towards pathogen detection and discovery.

\section{Keywords:}

Bats; experimental infection; rabies virus pathogenesis; thermography; surveillance

\section{Correspondence:}

C. E. Rupprecht. Division of HighConsequence Pathogens and Pathology, Centers for Disease Control and Prevention, 1600 Clifton Rd, NE, Mail Stop G-33, Atlanta, GA 30333, USA. Tel.: +1 404639 1050; Fax: +1 404639 1564; E-mail: cyr5@cdc.gov

This work was conducted at the United States Centers for Disease Control and Prevention, Atlanta, GA

Received for publication February 24, 2012

doi: 10.1111/zph.12019

\section{Summary}

Zoonotic disease surveillance is typically initiated after an animal pathogen has caused disease in humans. Early detection of potentially high-risk pathogens within animal hosts may facilitate medical interventions to cope with an emerging disease. To effectively spillover to a novel host, a pathogen may undergo genetic changes resulting in varying transmission potential in the new host and potentially to humans. Rabies virus (RABV) is one model pathogen to consider for studying the dynamics of emerging infectious diseases under both laboratory and field conditions. The evolutionary history of RABV is characterized by regularly documented spillover infections and a series of notable host shifts. Within this context, enhanced field surveillance to improve detection of spillover infections will require validated techniques to non-invasively differentiate infected from non-infected individuals. In this study, we evaluate the use of infrared thermography to detect thermal changes associated with experimental RABV infection in big brown bats (Eptesicus fuscus) in a captive colony. Our results indicated that $62 \%$ of rabid bats had detectable facial temperature decreases $\left(-4.6^{\circ} \mathrm{C}, \mathrm{SD} \pm 2.5\right)$ compared with pre-inoculation baseline values. These data suggest potential utility for discriminating rabid bats in natural field settings. In addition, focusing upon RABV circulating in the United States between 2008 and 2011, we confirmed spillover events of bat RABV among carnivores and identified cross-species transmission events caused by four lineages of RABV associated with insectivorous bats. Additionally, our analysis of RABV glycoprotein sequences identified substitutions in antigenic sites that may affect neutralizing activity associated with monoclonal antibodies proposed for use in human post-exposure prophylaxis. This study provides a glimpse into RABV pathobiology and spillover dynamics among and between bats and a variety of mesocarnivores. 


\section{Introduction}

Rabies is an acute progressive viral encephalitis (Family Rhabdoviridae, genus Lyssavirus) and remains one of the oldest and most thoroughly studied zoonoses associated with bats. Fundamentally, bats are believed to drive the natural history and evolution of lyssaviruses (Rupprecht et al., 2011). Among more than a dozen lyssaviruses associated with bats, Rabies virus (RABV) is the type species and most important member of the genus from a public health perspective. Concerning recent host shifts into mesocarnivores, the raccoon and south-central skunk RABVs are more closely related to bat RABV lineages than other carnivore lineages (Badrane and Tordo, 2001; Nadin-Davis and Real, 2011). How RABV disseminates into novel hosts and why spillover events result typically in dead end rather than sustained infections are unclear. Host taxonomy and social behaviour are suggested to play a role in RABV perpetuation, due to the frequency of interaction among con-specifics (Hughes et al., 2005). Rabies virus host range is also constrained by species barriers (Streicker et al., 2010).

Bats are unique among other mammals regarding thermoregulation, as many are heterothermic. For bats, metabolic activity and body temperature operates within a range of values on a daily basis, fluctuating regularly from a basal resting state to an active state of flight; both of these states can persist for several hours during torpor or daily foraging and even extend to several days or weeks as part of short- and long-distance seasonal migrations or when bats are in hibernation. Whether or not this widely variable metabolic activity has an influence on viral pathogenesis has not been addressed. A mathematical model parameterized from a longitudinal study of RABV in a Colorado population of big brown bats suggested a critical influence of hibernation in modulating seasonal infection dynamics (George et al., 2011). This model suggests that life-history patterns of many temperate-zone bats, coupled with sufficiently long incubation periods, facilitate RABV maintenance. Seasonal variability in bat mortality rates, and specifically low mortality during hibernation, promotes long-term host population viability. Within susceptible populations, sufficiently long incubation periods may allow enough infected individuals to enter hibernation and survive until the following year and possibly avoid an epizootic fadeout of infection. Further, studies on the influence of environmental temperature on the pathogenesis of experimental RABV infection in Mexican free-tailed bats (Tadarida brasiliensis) and little brown bats (Myotis lucifugus) provided evidence that minimal viral replication occurs in the host during experimentally induced hibernation, thus raising numerous questions concerning the interactions of environmental temperature on immune function in hibernating bats (Sulkin et al., 1960). Similarly, whether daily (e.g. colonial roosting or refuging) and/or seasonal (e.g. torpor) behavioural adaptations for dealing with temperature and energetic stress in temperate and tropical latitudes also impact intrinsic host susceptibility and ultimately pathogen evolution requires experimental evaluation (Streicker et al., 2012).

Despite the relatively high mutation rates of RNA virus genomes, including RABV, strong purifying selection is the primary force shaping the evolution of lyssaviruses (Rupprecht et al., 2011). All mammals are susceptible to RABV, likely due to evolutionarily conserved host cell receptors (Lentz et al., 1982; Holmes et al., 2002). However, which host cell molecules interact with RABV glycoproteins $(G)$ to facilitate entry into host cells in vivo, particularly with respect to viral dissemination into extraneural tissues, is less clear. The RABV G is the only exterior antigen, and is responsible for inducing specific RABV virus-neutralizing antibodies (Wunner, 2007). Understanding of antigenic variability of RABV G associated with different reservoir hosts is of particular importance for development of novel biologics for rabies prophylaxis, such as virus-neutralizing monoclonal antibodies (MAb) that are capable of binding to specific linear or conformational epitopes on the viral $\mathrm{G}$ (Marissen et al., 2005; Bakker et al., 2005; Sloan et al., 2007; Wang et al., 2011).

Novel schemes of preventing and controlling zoonotic diseases in wildlife can only be developed by integrating studies on host-pathogen ecologies (Hayman et al., in press). Within this context, enhanced surveillance under field conditions will require validated techniques to non-invasively differentiate infected from non-infected individuals. The multidisciplinary approach of this study consisted of examining infrared thermography and phylogenetic relationships among bat RABV variants that circulate in the United States, including those implicated in recent and historical spillover infections in humans and mesocarnivores. To gain insight into viral pathogenesis and identify clinical features among individuals, we evaluated the use of infrared thermography to detect thermographic changes associated with experimental RABV infection in captive big brown bats, as evaluated previously in raccoons (Procyon lotor) (Dunbar and MacCarthy, 2006). The prevalence of RABV is low in natural populations of bats with $\sim 0-0.5 \%$ infection rates reported (Kuzmin and Rupprecht, 2007). Our approach has potential to identify infected individuals and may improve the efficiency of active field surveillance efforts. Here, we utilize E. fuscus as an experimental animal model due to its broad geographic distribution, local abundance and complex genetic structure (Agosta, 2002; Turmelle et al., 2011). Additionally, big brown bats are 
the most frequently submitted bat species for rabies diagnosis in the United States, suggesting substantial human exposure (Blanton et al., 2011).

Laboratory-based surveillance is an essential tool for the detection and identification of novel lyssaviruses and RABV diversity (Freuling et al., 2011; Marston et al., 2012). Historically, both spillover events and host shifts have been revealed by public health surveillance systems (Flanagan et al., 2011). In the United States, RABV has been detected in all extant families of bats (Constantine, 2009). Bat RABV lineage diversity is partitioned into clades, which are associated with individual bat species or genera (Smith et al., 1995; Streicker et al., 2010). Most of these clades are monophyletic and appear to be dominated by intraspecific exchanges, suggesting that con-specifics maintain circulation of a RABV variant across areas that correspond with the host species geographic distribution, such as the big brown bat, Eptesicus fuscus, in North America or various Lasiurus sp., throughout the Americas (Sheeler-Gordon and Smith, 2001; Shankar et al., 2005; Nadin-Davis et al., 2010). Further, molecular and epidemiological studies have identified RABV variants associated with insectivorous bats in the majority of human rabies cases in the United States following the control and elimination of enzootic canine RABV (Velasco-Villa et al., 2008b; Petersen and Rupprecht, 2011).

\section{Materials and Methods}

\section{Experimental animals}

Twenty-seven big brown bats were collected from colonies in local buildings in GA, United States. Capture, handling and experimental procedures were performed in compliance with requirements of CDC Institutional Animal Care and Use Committee. Collection of animals occurred under GA Department of Natural Resources permit \#29-WSF-0514. Bats were marked individually with metal forearm bands and quarantined for approximately 1 month. Bats were held in groups of three to six animals in stainless steel cages $813 \times 305 \times 254 \mathrm{~mm}$. All cages were placed into an ABSL-2 facility at $24-27^{\circ} \mathrm{C}$ and $30-50 \%$ humidity.

\section{Experimental RABV infection}

The viral inoculum used in this study was a bat-associated RABV obtained from the salivary glands of a naturally infected gray fox (Urocyon cinereoargenteus) from Arizona during 2009 (CDC A09-2400). We chose this RABV because it demonstrated peripheral mortality in this experimental model. On day 0, 24 bats were inoculated intramuscularly with $25 \mu \mathrm{l}$ of viral suspension into both left and right masseter muscles (total volume $=50 \mu \mathrm{l}$ ). The virus dose was $10^{2.5} 50 \%$ mouse intra- cerebral lethal doses $\left(\mathrm{MICLD}_{50}\right)$ per $\mathrm{ml}$, as determined by titration in mice (Dean et al., 1996). Three control bats were not inoculated but co-housed with inoculated bats. Bats were either euthanized post-inoculation (pi) at planned time points (days 7, 14 and 21) or following clinical manifestation of rabies (i.e. paresis, paralysis, ataxia, atypical aggressive or reclusive behaviour).

\section{Infrared thermography}

Thermograms were collected between 09:00 and 15:30 hour on the day before inoculation and on days $7,14,15,18$, 19 and 21 pi. Each bat was restrained by hand at a distance of $0.6-0.7 \mathrm{~m}$ from a P640 thermal camera (FLIR Systems, North Billerica, MA, USA). Object parameters for the thermogram were either set when the thermogram was captured or corrected during processing. Parameters consisted of emissivity set at 0.96 and reflected temperature, atmospheric temperature and humidity set to the ambient conditions. For processing the thermograms, REPORTER 8.5 (FLIR Systems) software was used to acquire the mean facial temperature of individual bats. We evaluated the threshold of temperature for 'normal' bats assessing variations within the temperatures recorded from the day before inoculation (day-1 pi). The difference between each temperature recorded pi and the pre-inoculation temperature was calculated for individual bats. Due to a slight skew to the data and a limited sample sizes on certain days, we used a nonparametric evaluation for significance of the temperature changes. We compared the individual values to the interquartile range (IQR) from the difference between the 75th percentile and 25th percentile of the day -1 temperatures among individual bats. Temperature was then classified as positive (difference $>+\mathrm{IQR})$, steady $(-\mathrm{IQR}<$ difference $<+\mathrm{IQR})$ or negative (difference $<-\mathrm{IQR}$ ) for each day of thermogram collection. We considered the change significant if the difference was outside the $-\mathrm{IQR}$ to $+\mathrm{IQR}$ range.

\section{RABV diagnosis}

Necropsy was performed on all bats. Brain impressions were fixed in acetone at $-20^{\circ} \mathrm{C}$, and $\mathrm{RABV}$ antigens were detected by the direct fluorescent antibody test (dFA), using fluorescein isothiocyanate (FITC)-labelled monoclonal antibody (mAb) conjugate (Fujirebio Diagnostics, Inc., Malvern, PA, USA) as described (Dean et al., 1996).

\section{RNA extraction, sequencing, and phylogenetic reconstruction}

Brain specimens from carnivores and bats of various species were collected across the continental United States 
between 1991 and 2011 (Table 1). Total RNA was extracted from brain tissues using TRIzol ${ }^{\mathrm{TM}}$ according to manufacturer's instructions (Invitrogen, Carlsbad, CA, USA). Reverse transcription-polymerase chain reaction (RT-PCR) was performed as described (Kuzmin et al., 2003). The G gene was amplified as two overlapping fragments using primer combinations umf2/994b and 760f/308b (Table 2). The RT-PCR products were purified with Wizard ${ }^{\circledR}$ PCR Preps DNA Purification System (Promega, Madison, WI, USA), according to the manufacturer's recommendations and sequenced in forward and reverse directions using the Big Dye Terminator Cycle Sequencing Ready Reaction Kit, version 1.1 on an ABI3770 automatic sequencer (Applied Biosystems, Carlsbad, CA, USA). Editing and alignments of sequences were performed using BIOEDIT (Hall, 1999) and Clustal X (Larkin et al., 2007). Sequences were truncated to the coding region of the $G$ gene (1572 nucleotides) and analysed by Bayesian methods, implemented in BEAST, version 1.3 (Drummond and Rambaut, 2007). The optimal evolutionary model was chosen with MEGA, version 5.01 (Tamura et al., 2011). The general time-reversible model incorporating both invariant sites and a gamma distribution $(\mathrm{GTR}+\mathrm{I}+\mathrm{G})$ was the best model for the data set. Two simultaneous analyses, each with four Markov chains, were run for 10000000 generations and sampled every 1000 generations. The final inference of the tree was summarized from both runs with the initial $10 \%$ of samples discarded as burn-in. The remaining trees were used to build a $50 \%$ majority rule consensus reconstruction. Posterior probability values were used to assess support at each node. The trees were visualized using FIGTREE program, version 1.3.1 (Drummond and Rambaut, 2007).

\section{Results}

\section{Experimental infection}

Results of $R A B V$ challenge

Five infected bats per day were euthanized on days 7, 14, 19 and 21 pi and two per day on days 15 and 18 pi. With rare exception, bats displayed clinical signs of rabies on the day of euthanasia (Table 3). Among 24 inoculated bats, 21 were diagnosed as rabid by detection of RABV in the brain by $\mathrm{dFA}$ and three were dFA negative. The three dFA-negative bats included two animals euthanized on day 7 pi and one bat euthanized on day 21 pi (Table 3). Control bats were euthanized on day 38 pi. During this time, control bats did not display clinical signs of rabies, and RABV antigens were not detected in brain tissue by dFA.

\section{Thermography}

Pre-inoculation, the mean facial temperature of bats was $30.9^{\circ} \mathrm{C}$, and the median was $31.0^{\circ} \mathrm{C}$. The difference between the minimum and maximum facial temperature recorded was $3.7^{\circ} \mathrm{C}$, and the IQR was $1.5^{\circ} \mathrm{C}$. Bats euthanized on day $14,15,18$ and 19 pi had median temperatures $<30^{\circ} \mathrm{C}$. Additionally, on each of these days, $\geq 50 \%$ of the euthanized bats had a facial temperature decrease (individual facial temperature difference of less than $-1.5^{\circ} \mathrm{C}$ ) and none of the bats had facial temperature increases (Table 3). Bats euthanized on day 7 and 21 pi had a median facial temperature $\geq 30^{\circ} \mathrm{C}$ on each day; $\leq 40 \%$ of individuals presented decreased facial temperatures (Table 3). Two euthanized bats presented with increased facial temperatures on day 7 pi. The median facial temperatures for the three control bats ranged from $31.8^{\circ} \mathrm{C}$ on day 7 pi to $30.3^{\circ} \mathrm{C}$ on day 19 pi. The facial temperature difference at each sampled time for the control bats remained within $\pm 1.5^{\circ} \mathrm{C}$.

At the time of euthanasia, 13 bats (54\%) had a decreased facial temperature. The median decrease was $3.4^{\circ} \mathrm{C}$ (3.5 IQR), and the mean was $4.6^{\circ} \mathrm{C}( \pm 2.5 \mathrm{SD})$. Seven of the bats had facial temperature decreases of $3.4^{\circ} \mathrm{C}$ beyond pre-inoculation baseline. Ataxia and/or paralysis occurred in six of the seven bats. One rabid bat with a facial temperature decrease of $6.5^{\circ} \mathrm{C}$ was euthanized on day 14 pi and did not display observable clinical signs of rabies. One additional bat displayed ataxia and/or paralysis, and this individual's temperature decreased by $2.6^{\circ} \mathrm{C}$.

\section{Phylogenetic analysis}

In total, 13 major lineages were identified from the phylogenetic analysis of $\mathrm{G}$ gene sequences (Fig. 1; Genbank accession JQ685912, JQ685914, JQ685924, JQ685928, JQ685952, JQ685965, JQ685973, JQ685998-JQ68610, JQ686012, JQ686013, JX871837-JX871881). These were associated with: Tadarida brasiliensis (Tb), Parastrellus hesperus ( $\mathrm{Ph}$ ), Myotis sp. (My), Lasiurus intermedius (Li), Lasiurus borealis (Lb), Lasiurus cinereus (Lc), Lasionycteris noctivagans (Ln), Perimyotis subflavus (Ps), Antrozous pallidus (Ap) and Eptesicus fuscus (Ef). Variants associated with E. fuscus further segregated into four lineages: Ef-w1 and Ef-w2 with predominantly western distribution and Ef-e1 and Ef-e2 with predominantly eastern and central distribution. Moreover, viruses associated with the genus Myotis represent substantial diversity among bat RABV lineages. We identified seven putative cross-species transmission events among bats caused by viruses from four RABV lineages (Lb, Lc, Ap, Ps). Similarly, spillover infections with bat RABV (Ps, Ef-e1, My) were documented in carnivores (Table 1).

In the binding site for MAb CR57 [AA 229-231 (Marissen et al., 2005)], the substitution $L / \mathrm{P}_{231}$ was detected in the majority of bat RABV variants, except viruses from the lineage Ef-w2 and in one of the six available viruses from lineage Ef-e1 (both associated with big brown bats 
Table 1. Rabies virus (RABV) specimens referred in the present article

\begin{tabular}{|c|c|c|c|c|}
\hline CDC ID & Specimen origin & Lineage & State & $\begin{array}{l}\text { Year of } \\
\text { isolation }\end{array}$ \\
\hline A02-2971 & Parastrellus hesperus & $\mathrm{Ph}$ & CA & 2002 \\
\hline A02-2972 & Parastrellus hesperus & $\mathrm{Ph}$ & $A Z$ & 2002 \\
\hline A08-1210 & Lasionycteris noctivagans & Ps & $\mathrm{FL}$ & 2008 \\
\hline A09-0186 & Lasiurus borealis & $\mathrm{Lb}$ & NC & 2009 \\
\hline A09-1077 & Lasiurus borealis & $\mathrm{Lb}$ & NC & 2010 \\
\hline A09-2403 & Urocyon cinereoargenteus & Ef-w1 & $A Z$ & 2009 \\
\hline A09-2561 & Eptesicus fuscus & Ef-e1 & IA & 2010 \\
\hline A09-3497 & Myotis sp. & My & $A Z$ & 2009 \\
\hline A10-2051 & Lasiurus borealis & $\mathrm{Lb}$ & NC & 2010 \\
\hline A10-2054 & Eptesicus fuscus & Ef-e2 & NC & 2010 \\
\hline A10-2056 & Eptesicus fuscus & Ef-e2 & NC & 2010 \\
\hline A10-2057 & Eptesicus fuscus & Ef-w2 & NC & 2010 \\
\hline A10-3023 & Eptesicus fuscus & Ps & $\mathrm{AL}$ & 2009 \\
\hline A10-3565 & Lasionycteris noctivagans & Ln & $A L$ & 2010 \\
\hline A10-3633 & Perimyotis subflavus & Ps & NC & 2009 \\
\hline A10-3653 & Lasiurus intermedius & $\mathrm{Li}$ & $\mathrm{FL}$ & 2008 \\
\hline A10-3671 & Tadarida brasiliensis & $\mathrm{Tb}$ & $\mathrm{FL}$ & 2009 \\
\hline A10-3672 & Lasionycteris noctivagans & Ln & $\mathrm{AL}$ & 2009 \\
\hline A $10-4443$ & Eptesicus fuscus & LC & VA & 2010 \\
\hline A10-5073 & Myotis sp. & My & $A Z$ & 2009 \\
\hline A10-5102 & Perimyotis subflavus & Ps & NC & 2010 \\
\hline A10-5103 & Eptesicus fuscus & Ef-e1 & NC & 2010 \\
\hline A10-5104 & Perimyotis subflavus & Ps & NC & 2010 \\
\hline A10-5170 & Myotis sp. & My & ID & 2010 \\
\hline A10-5195 & Eptesicus fuscus & Ef-e2 & VA & 2010 \\
\hline A10-5458 & Perimyotis subflavus & Ps & NC & 2010 \\
\hline A10-6958 & Urocyon cinereoargenteus & Ef-w2 & OR & 2010 \\
\hline A10-7347 & Urocyon cinereoargenteus & My & OR & 2010 \\
\hline A10-7348 & Urocyon cinereoargenteus & My & OR & 2010 \\
\hline A11-0152 & Homo sapiens & Ps & $\mathrm{WI}$ & 2011 \\
\hline A11-0694 & Eptesicus fuscus & Ef-e2 & TN & 2011 \\
\hline A11-0695 & Lasiurus borealis & $\mathrm{Lb}$ & TN & 2011 \\
\hline A11-0696 & Eptesicus fuscus & Ef-e2 & TN & 2011 \\
\hline A11-0697 & Lasionycteris noctivagans & $\operatorname{Ln}$ & TN & 2011 \\
\hline A11-0699 & Perimyotis subflavus & Ps & TN & 2011 \\
\hline A11-0701 & Eptesicus fuscus & Ef-e1 & TN & 2011 \\
\hline A11-0702 & Lasionycteris noctivagans & Ln & IL & 2011 \\
\hline A11-0703 & Urocyon cinereoargenteus & Ef-w2 & OR & 2011 \\
\hline A11-0704 & Urocyon cinereoargenteus & Ef-w2 & OR & 2011 \\
\hline A11-1043 & Canis latrans & Ef-w2 & OR & 2011 \\
\hline A11-1200 & Lasiurus borealis & $\mathrm{Lb}$ & NC & 2010 \\
\hline A11-1201 & Lasionycteris noctivagans & $\operatorname{Ln}$ & $\mathrm{Ml}$ & 2009 \\
\hline A11-1202 & Myotis thysanodes & My & CA & 1991 \\
\hline A11-1203 & Antrozous pallidus & LC & CA & 1994 \\
\hline A11-1204 & Perimyotis subflavus & Ps & NC & 2010 \\
\hline A11-1205 & Lasiurus borealis & $\mathrm{Lb}$ & NC & 2010 \\
\hline A11-1206 & Antrozous pallidus & Ap & NC & 1993 \\
\hline A11-1733 & Eptesicus fuscus & Ef-w1 & $A Z$ & 2011 \\
\hline A11-1735 & Parastrellus hesperus & Ap & $A Z$ & 2011 \\
\hline A11-1742 & Lasiurus borealis & $\mathrm{Lb}$ & GA & 2011 \\
\hline A11-1743 & Eptesicus fuscus & Ef-e1 & GA & 2011 \\
\hline A11-1744 & Lasiurus borealis & $\mathrm{Lb}$ & GA & 2011 \\
\hline A11-1745 & Lasiurus borealis & Lb & GA & 2011 \\
\hline A11-1746 & Lasiurus borealis & Ps & GA & 2011 \\
\hline A11-1747 & Eptesicus fuscus & Ef-e1 & GA & 2011 \\
\hline
\end{tabular}

Table 1. (Continued)

\begin{tabular}{lllll}
\hline CDC ID & Specimen origin & Lineage & State & $\begin{array}{l}\text { Year of } \\
\text { isolation }\end{array}$ \\
\hline A11-1751 & Tadarida brasiliensis & Tb & GA & 2011 \\
A11-1753 & Lasiurus borealis & Lb & GA & 2011 \\
A11-1754 & Lasiurus borealis & Lb & GA & 2011 \\
A11-1769 & Lasiurus borealis & Lb & NC & 2011 \\
A11-1771 & Eptesicus fuscus & Ef-e2 & NC & 2011 \\
A11-1786 & Eptesicus fuscus & Ef-W1 & AZ & 2011 \\
A11-1787 & Eptesicus fuscus & Ef-w1 & AZ & 2011 \\
A11-1789 & Tadarida brasiliensis & Tb & GA & 2011 \\
A11-2738 & Urocyon cinereoargenteus & My & OR & 2011 \\
A11-3055 & Eptesicus fuscus & Lb & MO & 2011 \\
A11-3057 & Eptesicus fuscus & Ef-e2 & MO & 2011 \\
A11-3058 & Eptesicus fuscus & Ef-e1 & MO & 2011 \\
A09-2400 & Urocyon cinereoargenteus & Ef-w1 & AZ & 2009 \\
A11-5737 & Vulpes vulpes & Ps & VA & 2011 \\
A11-6191 & Vulpes vulpes & Ef-e1 & WV & 2011 \\
\hline
\end{tabular}

[Eptesicus fuscus] and in both available viruses associated with pallid bats (Antrozous pallidus; lineage Ap), which retained $\mathrm{L}_{231}$. In addition, RABV associated with Mexican free-tailed bats (Tadarida brasiliensis; lineage $\mathrm{Tb}$ ) had $S_{231 .}$

Numerous and variable substitutions were detected in the binding site for MAb CR4098 within antigenic site III [AA 330-338; (Bakker et al., 2005)]. For example, substitution $\mathrm{V} / \mathrm{I} / \mathrm{F}_{332}$ was documented in several RABV variants, associated with big brown bats (Ef-w1, Ef-w2, Ef-e2). Substitution $\mathrm{N} / \mathrm{D}_{336}$ was detected in the majority of viruses from lineage Ef-e2. However, no sequences contained substitutions in the binding sites for MAbs CR57 and CR4098 simultaneously. Moreover, the presence of combination $\mathrm{D}_{336}-\mathrm{K}_{346}$ was detected in the RABV variant, associated with the Histiotis montanus bat, broadly distributed in South America, within the binding site of MAb RAB1 also known as HuMAb 17C7 (Sloan et al., 2007; Wang et al., 2011).

\section{Discussion}

These preliminary findings contribute to our understanding of the epizootiology and pathogenesis of RABV in bats. As with other etiological agents associated with bats, a greater appreciation is needed at the individual hostpathogen level, predicated with the diversity of outcomes from the variables of variant, dose, route and host population. Bats differ from other mammals in that an individual's body temperature when at rest during any season typically approximates their environment (Hock, 1951). The metabolic rate reflects this change so that metabolism is influenced by body temperature. The experimental infection data suggest a link between thermal changes 
Table 2. Primers used in this study

\begin{tabular}{llll}
\hline Primer & Sense & Viral locus & Sequence $\left(5^{\prime}-3^{\prime}\right)$ \\
\hline Umf2 & + & $\mathrm{M}-\mathrm{G}$ & ATGGTGCCRTTRAATYGCTGCATT \\
g994b & - & $\mathrm{G}$ & TTGAATATRGTRTATGCCTT \\
g760 & + & $\mathrm{G}$ & CTDATGGAYGGAACNTGGGT \\
$308 \mathrm{deg}$ & - & $\mathrm{L}-\mathrm{G}$ & ACCTCTCCDGGATCGAKCT \\
\hline
\end{tabular}

detectable peri-mortem in big brown bats and clinical display of rabies. Bats displaying multiple signs of rabies, including those associated with an acute progressive encephalopathy (i.e. ataxia, paralysis), had substantially reduced facial temperatures at euthanasia or humane experimental endpoints (Fig. 2). Some bats had detectable temperature changes without acute clinical signs. These individuals may have been euthanized before manifestation of illness, warranting further investigation into infrared thermography's ability to enhance earlier detection of rabid animals. Alternatively, individual temperature variations may have been greater than the variation captured from the pre-inoculation baseline thermograms. While some individual positive temperature changes were observed, we were unable to determine causation from our data. Future research is needed to address the precise timing of changes in facial and body temperature in relation to RABV pathogenesis.

One recent model highlighted the slowing effects of hibernation on metabolic and viral activity maintained in infected individuals until arousal, when susceptible individuals from the annual birth pulse became infected (George et al., 2011). Previous research on the effects of high ambient temperature on various stages of experimental RABV infection in laboratory mice found that exposure to high ambient temperature late in the incubation period delayed clinical manifestation, decreased

Table 3. Facial temperature of individual bats before inoculation of rabies virus and at time of euthanasia along with observed clinical signs

\begin{tabular}{|c|c|c|c|c|c|c|}
\hline \multirow[b]{2}{*}{ Animal ID } & \multirow[b]{2}{*}{ Day euthanized } & \multicolumn{3}{|c|}{ Facial temperature ${ }^{\circ} \mathrm{C}$} & \multirow[b]{2}{*}{ Clinical signs } & \multirow[b]{2}{*}{ dFA diagnosis } \\
\hline & & Pre-inoculation & Day euthanized & Change & & \\
\hline \multicolumn{7}{|l|}{ Inoculated } \\
\hline 179 & 7 & 29.3 & 32.3 & 3 & WNL & + \\
\hline 180 & 7 & 30.1 & 32.3 & 2.2 & WNL & + \\
\hline 181 & 7 & 32.2 & 30 & -2.2 & WNL & + \\
\hline 182 & 7 & 30.5 & 30.9 & 0.4 & WNL & - \\
\hline 184 & 7 & 29.6 & 30.1 & 0.5 & WNL & - \\
\hline 190 & 14 & 30.1 & 30.6 & 0.5 & WNL & + \\
\hline 197 & 14 & 31.6 & 29.7 & -1.9 & WNL & + \\
\hline 198 & 14 & 31 & 30.7 & -0.3 & WNL & + \\
\hline 199 & 14 & 32 & 25.5 & -6.5 & WNL & + \\
\hline 376 & 14 & 30.9 & 27.9 & -3 & WNL & + \\
\hline 192 & 15 & 29.8 & 28.6 & -1.2 & $A / L, V, T$ & + \\
\hline 362 & 15 & 31.4 & 24.6 & -6.8 & $P, T, X$ & + \\
\hline 178 & 18 & 32 & 28.9 & -3.1 & $\mathrm{~A} / \mathrm{L}, \mathrm{V}, \mathrm{T}, \mathrm{A}$ & + \\
\hline 188 & 18 & 31.8 & 28.8 & -3 & $A, V$ & + \\
\hline 189 & 19 & 32.2 & 23.4 & -8.8 & $A / L, V, N, P, T, X$ & + \\
\hline 191 & 19 & 31.9 & 22.7 & -9.2 & $L, V, N, P, X$ & + \\
\hline 193 & 19 & 30.9 & 24.9 & -6 & $L, V, P, T, X$ & + \\
\hline 195 & 19 & 30.2 & 29.6 & -0.6 & $A, V, N, T, D$ & + \\
\hline 372 & 19 & 28.45 & 25.9 & -2.55 & $L, V, S, T, X$ & + \\
\hline 177 & 21 & 30.6 & 30 & -0.6 & $A, V, T$ & + \\
\hline 194 & 21 & 31.7 & 27.8 & -3.9 & $L, V, N, S, T, P$ & + \\
\hline 196 & 21 & 31.3 & 27.9 & -3.4 & $A / L, V, N, S, P, T, X$ & + \\
\hline 370 & 21 & 30.3 & 30.7 & 0.4 & WNL & - \\
\hline 375 & 21 & 31.3 & 30.7 & -0.6 & $A, V$ & + \\
\hline \multicolumn{7}{|c|}{ Uninoculated controls } \\
\hline 364 & 38 & 30.8 & $31.3^{*}$ & -0.5 & WNL & - \\
\hline 379 & 38 & 31.5 & $31.0 *$ & 0.5 & WNL & - \\
\hline 400 & 38 & 31.4 & $30.3^{*}$ & 1.1 & WNL & - \\
\hline
\end{tabular}

*Temperature from last day of thermogram collection, day 21 pi.

A, increased aggression; D, dysphasia; X, ataxia; P, paralysis/paresis; T, tremors; L, lethargy; V, odd vocalization; S, seizure; N, nystagmus; A/L, minor aggression; WNL, within normal limits. 


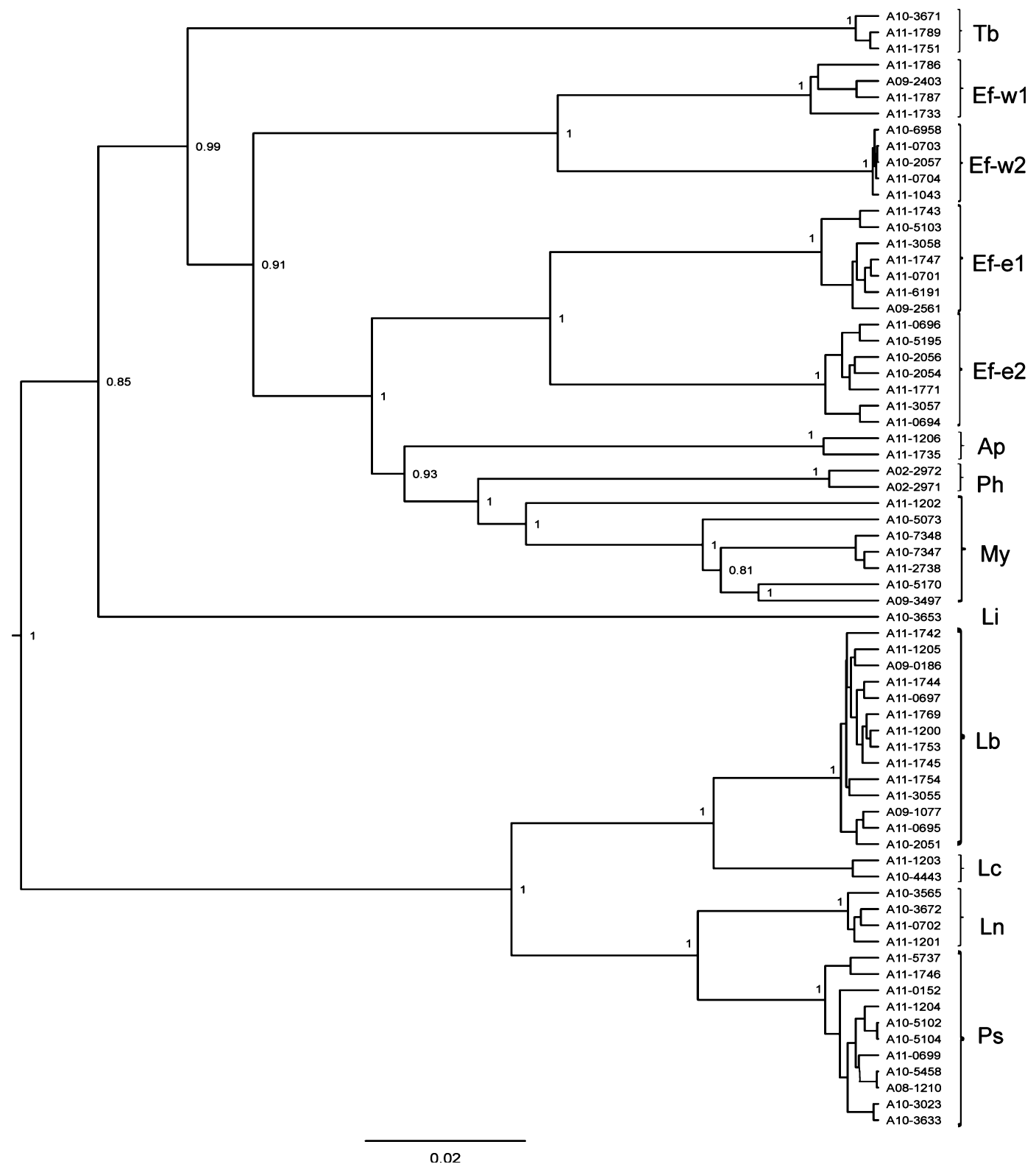

Fig. 1. Phylogenetic tree of bat RABV glycoprotein gene sequences rooted at the midpoint, and truncated to the coding region (1572 nucleotides), posterior probability values shown for key nodes.

mortality and increased frequency of an abortive infection, but exposure to high ambient temperature after clinical manifestation did not affect the course of disease (Hock, 1951; Bell and Moore, 1974). As torpid hibernators, bats can adjust to a wide range of ambient temperatures and reduce their body temperature by $1-2^{\circ} \mathrm{C}$ above the ambient temperature, thus drastically decreasing their metabolic rates. The adaptive value of this state is to conserve energy, although hibernating animals arouse periodically and their body temperature metabolic rate return to normal for a period of usually $<24 \mathrm{~h}$ (Pengelley and
Fisher, 1963; Geiser et al., 1990). Torpor induces leukopenia and during this period lower levels of lymphocyte proliferation and antibody production can be observed, which is hypothesized to be beneficial in terms of energy conservation (Bouma et al., 2010). An appropriate immune response operates most efficiently within narrow temperature confines, constrained by the unique properties of an individual's physiology. However, recent studies have suggested that the immune system may be at rest, or depressed, in torpid or hibernating mammals (Bouma et al., 2010). Support of this concept has been suggested 

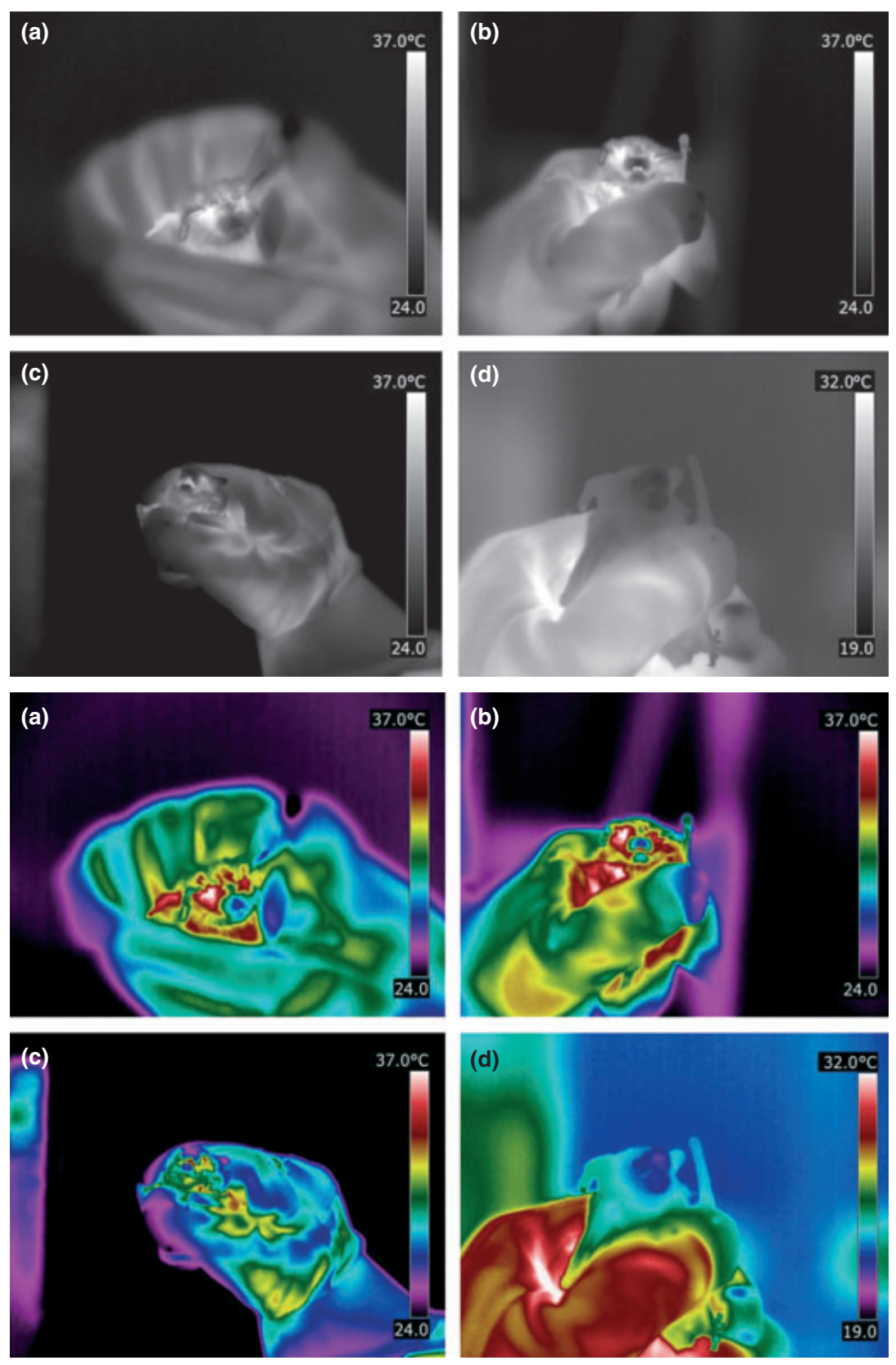

Fig. 2. Individual facial thermograms shown in greyscale (top) and colour (bottom) for bat 191 observed at (a) day -1 (pre-inoculation) $=37.8^{\circ} \mathrm{C}$; (b) day 7 post-inoculation (pi) $=37.9^{\circ} \mathrm{C}$; (c) day $14 \mathrm{pi}=34.3^{\circ} \mathrm{C}$ and (d) day $19 \mathrm{pi}=24.0^{\circ} \mathrm{C}$ (note: temperature scale modified).

recently as a main factor allowing colonization of Geomyces destructans, the fungal agent associated with White Nose Syndrome in North America, which reproduces optimally during winter periods when many temperate bats undergo torpor (Lorch et al., 2011). The impact of variation in host metabolism resulting from short- or long-distance migration and torpor or hibernation behaviours deserves greater introspection with regard to perpetuation of infectious diseases in bat populations.
The association between geography and the rate of RABV evolution reflects differences in the seasonality of RABV transmission throughout diverse ecotypes (Streicker et al., 2012). As such, epizootiologic factors associated with RABV in bats include regional population differences and the effects of roosting habits, on both the proportion of rabid bats and numbers of bats submitted for diagnosis (Patyk et al., 2012). Additionally, roosting ecology influences estimates of RABV prevalence, with 
significantly higher prevalence among passive surveillance submissions of non-synanthropic bat species compared with synanthropic bat species submitted for rabies diagnosis in the United States, a trend not evident in active surveillance reports (Klug et al., 2011). Patterns of RABV circulation in bats also appear to be different from those described for carnivores (Blanton et al., 2011). For example, in Texas, rabid skunk cases peak during March and April (Oertli et al., 2009). Host species susceptibility needs to be balanced with pathogenicity of the virus, which is directly associated with host population density, mobility, sex and age composition, frequency of social contacts and patterns of behaviour (Sterner and Smith, 2006). As with any successful virus, these variables should ensure that rabid animals transmit virus to at least one other susceptible individual (i.e. $R_{0} \geq 1$ ). Individual bats in large colonies may experience multiple exposures to RABV throughout their lifetime (Constantine et al., 1972). Repeated sub-lethal exposures may provide a natural booster, confer significant immunological memory and reduced susceptibility to RABV (Turmelle et al., 2010). However, infectious virus and/or antigens are not always present in the salivary glands of rabid bats (Davis et al., 2012). In addition, the immunogenicity of RABV variants likely differs across host reservoir species. The precise amount of virus introduced by bite or non-bite exposures necessary for a productive infection and lethal disease among insectivorous bats remains unknown.

In this report, phylogenetic analysis of bat RABVs based on their G gene sequences revealed similar phylogenetic groupings as reported previously utilizing other viral genes (Smith et al., 1995; Velasco-Villa et al., 2006; Streicker et al., 2010; Nadin-Davis and Real, 2011). This is expected, given that major forces of RABV evolution include point mutations, lack of proofreading mechanisms and strong constraints applied by purifying selection. We also confirm that tri-coloured bats (Perimyotis subflavus) maintain circulation of a similar but distinct RABV lineage from that associated with the silver-haired bat (L. noctivagans), as was suggested from $\mathrm{N}$-gene sequences (Franka et al., 2006). Initially, these two viruses were considered one variant, based on the reactivity patterns with anti-nucleocapsid MAbs and partial N-gene sequences (Smith, 1988; Morimoto et al., 1996; Messenger et al., 2003). We also documented spillover of selected RABVs among bats and also to carnivores. One human rabies case in 2010 was the result of infection with a Ps RABV variant. Furthermore, viruses from My, Ef-w1 and Ef-w2 were associated with outbreaks in mesocarnivores in Arizona and Oregon during 2008-2010, consistent with similar findings documented during 2001-2005 in Arizona (Leslie et al., 2006). Although substantial diversity was demonstrated for RABVs associated with Myotis bats, phenotypic identification of species, and particularly degraded specimens potentially received by state health laboratories, were beyond the scope of this study, and likely require robust morphological and genetic assessment for further resolution of specific RABV associations in this genus (Stadelmann et al., 2007).

Our analysis of binding sites for putative RABV-neutralizing MAbs identified several G gene substitutions. Previous experiments with escape mutants demonstrated that substitution $\mathrm{L} / \mathrm{P} / \mathrm{S}_{231}$ did not preclude virus neutralization by MAb CR57 (Marissen et al., 2005). However, substitution $\mathrm{N} / \mathrm{D}_{336}$ precluded virus neutralization by MAb CR4098 in the escape mutant studies (Bakker et al., 2005). No sequences contained substitutions in the both binding sites for MAbs CR57 and CR4098 simultaneously, which supports the use of a MAb cocktail as a replacement of conventional polyclonal rabies immune globulin for human PEP (Goudsmit et al., 2006). In contrast, the proposed use of a single MAb for human PEP seems inappropriate.

The implications of spillover infections and host shifts for public and veterinary health are numerous. Human exposures to rabid carnivores may occur in localities believed to be 'free' of rabies and therefore not attract the necessary medical care including appropriate postexposure prophylaxis. A preventable example of such an exposure resulted in a human rabies case in the United States acquired from a bite of a rabid canine (potentially a fox) in Oaxaca, Mexico, which was subsequently characterized as a bat RABV associated with T. brasiliensis (Velasco-Villa et al., 2008a). Early detection of diseased animals within a population may improve surveillance opportunities, reduce economic loss and minimize the loss of exposed humans, domestic species and wildlife (Dunbar et al., 2009). Further research is needed to determine the utility of thermography in predicting RABV infection under experimental and field conditions. Such applications may be limited to providing an additional record in determining a humane endpoint during experimental infections or may have potential use in pathogen discovery and outbreak response by enhanced surveillance at roosts. The use of thermography will depend on when notable temperature changes occur in relation to disease progression. Thermography is harmless for subjects, and can be performed without anaesthesia. This technique has shown promise for detecting fever and inflammation and is also useful for postsurgical, orthopaedic and neurological monitoring. However, diseases with non-specific clinical features (i.e. fever) may produce similar thermal patterns, thus precluding its utility for providing a specific diagnosis, as opposed to generalized illness. With further studies and the advancement of this technology, thermography used in a clinical setting may become a 
standard tool in both human and veterinary medicine for improved surveillance, prevention and control.

\section{Acknowledgements}

The authors thank staff of the Rabies Team and Animal Resources Branch of CDC (Atlanta, GA, USA) for their expertise. Special thanks go to Felix Jackson and Katherine Paul for excellent technical assistance during this study. The authors also thank the state health departments for submission of samples for analysis.

\section{Disclaimer}

Use of trade names and commercial sources are for identification only and do not imply endorsement by the US Department of Health and Human Services or US Department of Agriculture. The findings and conclusions in this report are those of the authors and do not necessarily represent the views of their institutions.

\section{References}

Agosta, S. J., 2002: Habitat use, diet and roost selection by the big brown bat (Eptesicus fuscus) in North America: a case for conserving an abundant species. Mammal. Rev. 32, 179198.

Badrane, H., and N. Tordo, 2001: Host switching in Lyssavirus history from the Chiroptera to the Carnivora orders. J. Virol. 75, 8096-8104.

Bakker, A. B. H., W. E. Marissen, R. A. Kramer, A. B. Rice, W. C. Weldon, M. Niezgoda, C. A. Hanlon, S. Thijsse, H. H. J. Backus, and J. De Kruif, 2005: Novel human monoclonal antibody combination effectively neutralizing natural rabies virus variants and individual in vitro escape mutants. J. Virol. 79, 9062-9068.

Bell, J., and G. Moore, 1974: Effects of high ambient temperature on various stages of rabies virus infection in mice. Infect. Immun. 10, 510-515.

Blanton, J. D., D. Palmer, J. Dyer, and C. E. Rupprecht, 2011: Rabies surveillance in the United States during 2010. J. Am. Vet. Med. Assoc. 239, 773-783.

Bouma, H. R., H. V. Carey, and F. G. M. Kroese, 2010: Hibernation: the immune system at rest? J. Leukoc. Biol. 88, 619-624.

Constantine, D., 2009: Bat Rabies and Other Lyssavirus Infections. USGS circular 1329, Reston, VA, USA.

Constantine, D. G., R. W. Emmons, and J. D. Woodie, 1972: Rabies virus in nasal mucosa of naturally infected bats. Science 175, 1255-1256.

Davis, A., P. Gordy, R. Rudd, J. A. Jarvis, and R. A. Bowen, 2012: Naturally acquired rabies virus infections in wildcaught bats. Vector Borne Zoonotic Dis. 12, 55-60.

Dean, D. J., M. K. Abelseth, and P. Atanasiu, 1996: The flourescent antibody test. In: Meslin, F. X., M. M. Kaplan, and
H. Koprowski (eds), Laboratory Techniques in Rabies, pp. 83-93. World Health Organization, Geneva, Switzerland. Drummond, A., and A. Rambaut, 2007: BEAST: Bayesian evolutionary analysis by sampling trees. BMC Evol. Biol. 7, 214222.

Dunbar, M., and K. MacCarthy, 2006: Use of infrared thermography to detect signs of rabies infection in raccoons (Procyon lotor). J. Zoo. Wildl. Med. 37, 518.

Dunbar, M. R., S. R. Johnson, J. C. Rhyan, and M. McCollum, 2009: Use of infrared thermography to detect thermographic changes in mule deer (Odocoileus hemionus) experimentally infected with foot-and-mouth disease. J. Zoo Wildl. Med. 40, 296-301.

Flanagan, M., C. Parrish, S. Cobey, G. Glass, R. Bush, and T. Leighton, 2011: Anticipating the species jump: surveillance for emerging viral threats. Zoonoses and Public Health 59, 155-163. Franka, R., D. G. Constantine, I. Kuzmin, A. Velasco-Villa, S. A. Reeder, D. Streicker, L. A. Orciari, A. J. Wong, J. D. Blanton, and C. E. Rupprecht, 2006: A new phylogenetic lineage of rabies virus associated with western pipistrelle bats (Pipistrellus hesperus). J. Gen. Virol. 87, 2309-2321.

Freuling, C. M., M. Beer, F. J. Conraths, S. Finke, B. Hoffmann, B. Keller, J. Kliemt, T. C. Mettenleiter, E. Mühlbach, J. P. Teifke, and T. Müller, 2011: Novel lyssavirus in Natterer's bat, Germany. Emerg. Infect. Dis. 17, 1519-1522.

Geiser, F., S. Hiebert, and G. Kenagy, 1990: Torpor bout duration during the hibernation season of two sciurid rodents: interrelations with temperature and metabolism. Physiol. Zool. 63, 489-503.

George, D. B., C. T. Webb, M. L. Farnsworth, T. J. O'Shea, R. A. Bowen, D. L. Smith, T. R. Stanley, L. E. Ellison, and C. E. Rupprecht, 2011: Host and viral ecology determine bat rabies seasonality and maintenance. Proc. Natl Acad. Sci. USA 108, 10208-10213.

Goudsmit, J., W. E. Marissen, W. C. Weldon, M. Niezgoda, C. A. Hanlon, A. B. Rice, J. Kruif, B. Dietzschold, A. B. Bakker, and C. E. Rupprecht, 2006: Comparison of an anti-rabies human monoclonal antibody combination with human polyclonal anti-rabies immune globulin. J. Infect. Dis. 193, 796-801.

Hall, T. A., 1999: BioEdit: a user-friendly biological sequence alignment editor and analysis program for Windows 95/98/ NT. Nucleic Acids Symp. Ser. 41, 95-98.

Hayman, D. T. S., R. A. Bowen, P. M. Cryan, G. F. McCracken, T. J. O'Shea, A. Peel, A. T. Gilbert, C. T. Webb, and J. L. N. Wood. in press: Ecology of zoonotic infectious diseases in bats: current knowledge and future directions. Zoonoses and Public Health

Hock, R. J., 1951: The metabolic rates and body temperatures of bats. Biol. Bull. 101, 289-299.

Holmes, E. C., C. H. Woelk, R. Kassis, and H. Bourhy, 2002: Genetic constraints and the adaptive evolution of rabies virus in nature. Virology 292, 247-257.

Hughes, G. J., L. A. Orciari, and C. E. Rupprecht, 2005: Evolutionary timescale of rabies virus adaptation to North 
American bats inferred from the substitution rate of the nucleoprotein gene. J. Gen. Virol. 86, 1467-1474.

Klug, B. J., A. S. Turmelle, J. A. Ellison, E. F. Baerwald, and R. M. Barclay, 2011: Rabies prevalence in migratory tree-bats in Alberta and the influence of roosting ecology and sampling method on reported prevalence of rabies in bats. J. Wildl. Dis. 47, 64-77.

Kuzmin, I., and C. Rupprecht, 2007: Bat rabies. In: Jackson, A. (ed.), Rabies, pp. 259-308. Elseiver, Oxford, UK.

Kuzmin, I. V., L. A. Orciari, Y. T. Arai, J. S. Smith, C. A. Hanlon, Y. Kameoka, and C. E. Rupprecht, 2003: Bat lyssaviruses (Aravan and Khujand) from Central Asia: phylogenetic relationships according to $\mathrm{N}, \mathrm{P}$ and $\mathrm{G}$ gene sequences. Virus Res. 97, 65-79.

Larkin, M. A., G. Blackshields, N. P. Brown, R. Chenna, P. A. McGettigan, H. McWilliam, F. Valentin, I. M. Wallace, A. Wilm, R. Lopez, J. D. Thompson, T. J. Gibson, and D. G. Higgins, 2007: Clustal W and Clustal X version 2.0. Bioinformatics 23, 2947-2948.

Lentz, T. L., T. G. Burrage, A. L. Smith, J. Crick, and G. H. Tignor, 1982: Is the acetylcholine receptor a rabies virus receptor? Science 215, 182-184.

Leslie, M., S. Messenger, R. Rohde, J. Smith, R. Cheshier, C. Hanlon, and C. Rupprecht, 2006: Bat-associated rabies virus in skunks. Emerg. Infect. Dis. 12, 1274-1277.

Lorch, J. M., C. U. Meteyer, M. J. Behr, J. G. Boyles, P. M. Cryan, A. C. Hicks, A. E. Ballmann, J. T. H. Coleman, D. N. Redell, and D. A. M. Reeder, 2011: Experimental infection of bats with Geomyces destructans causes white-nose syndrome. Nature 480, 376-378.

Marissen, W. E., R. A. Kramer, A. Rice, W. C. Weldon, M. Niezgoda, M. Faber, J. W. Slootstra, R. H. Meloen, M. Clijsters-van der Horst, T. J. Visser, M. Jongeneelen, S. Thijsse, M. Throsby, J. de Kruif, C. E. Rupprecht, B. Dietzschold, J. Goudsmit, and A. B. Bakker, 2005: Novel rabies virus-neutralizing epitope recognized by human monoclonal antibody: fine mapping and escape mutant analysis. J. Virol. 79, 4672-4678.

Marston, D. A., D. L. Horton, C. Ngeleja, K. Hampson, L. M. McElhinney, A. C. Banyard, D. Haydon, S. Cleaveland, C. E. Rupprecht, and M. Bigambo, 2012: Ikoma lyssavirus, highly divergent novel lyssavirus in an African civet. Emerg. Infect. Dis. 18, 664.

Messenger, S. L., J. S. Smith, L. A. Orciari, P. A. Yager, and C. E. Rupprecht, 2003: Emerging pattern of rabies deaths and increased viral infectivity. Emerg. Infect. Dis. 9, 151-154.

Morimoto, K., M. Patel, S. Corisdeo, D. C. Hooper, Z. F. Fu, C. E. Rupprecht, H. Koprowski, and B. Dietzschold, 1996: Characterization of a unique variant of bat rabies virus responsible for newly emerging human cases in North America. Proc. Natl Acad. Sci. USA 93, 56535658.

Nadin-Davis, S. A., and L. A. Real, 2011: Molecular phylogenetics of the lyssaviruses - insights from a coalescent approach. Adv. Virus Res. 79, 203-238.
Nadin-Davis, S. A., Y. Feng, D. Mousse, A. I. Wandeler, and S. Aris-Brosou, 2010: Spatial and temporal dynamics of rabies virus variants in big brown bat populations across Canada: footprints of an emerging zoonosis. Mol. Ecol. 19, 21202136.

Oertli, E. H., P. J. Wilson, P. R. Hunt, T. J. Sidwa, and R. E. Rohde, 2009: Epidemiology of rabies in skunks in Texas. J. Am. Vet. Med. Assoc. 234, 616-620.

Patyk, K., A. Turmelle, J. D. Blanton, and C. E. Rupprecht, 2012: Trends in national surveillance data for bat rabies in the United States: 2001-2009. Vector Borne Zoonotic Dis. 12, $1-9$.

Pengelley, E. T., and K. C. Fisher, 1963: The effect of temperature and photoperiod on the yearly hibernating behavior of captive golden-mantled ground squirrels (Citellus lateralis tescorum). Can. J. Zool. 41, 1103-1120.

Petersen, B. W., and C. E. Rupprecht, 2011: Human rabies epidemiology and diagnosis. In: Tkachev, S. (ed.), Non-Flavivirus Encephalitis, pp. 247-278. InTech, Rijeka, Croatia.

Rupprecht, C. E., A. Turmelle, and I. V. Kuzmin, 2011: A perspective on lyssavirus emergence and perpetuation. Curr. Opin. Virol. 1, 662-670.

Shankar, V., L. A. Orciari, C. De Mattos, I. V. Kuzmin, W. J. Pape, T. J. O'Shea, and C. E. Rupprecht, 2005: Genetic divergence of rabies viruses from bat species of Colorado, USA. Vector Borne Zoonotic Dis. 5, 330-341.

Sheeler-Gordon, L. L., and J. S. Smith, 2001: Survey of bat populations from Mexico and Paraguay for rabies. J. Wildl. Dis. 37, 582-593.

Sloan, S. E., C. Hanlon, W. Weldon, M. Niezgoda, J. Blanton, J. Self, K. J. Rowley, R. B. Mandell, G. J. Babcock, W. D. Thomas, C. E. Rupprecht, and D. M. Ambrosino, 2007: Identification and characterization of a human monoclonal antibody that potently neutralizes a broad panel of rabies virus isolates. Vaccine 25, 2800-2810.

Smith, J. S., 1988: Monoclonal antibody studies of rabies in insectivorous bats of the United States. Rev. Infect. Dis. 10, S637-S643.

Smith, J. S., L. A. Orciari, and P. A. Yager, 1995: Molecular epidemiology of rabies in the United States. Semin. Virol. 6, 387-400.

Stadelmann, B., L. K. Lin, T. H. Kunz, and M. Ruedi, 2007: Molecular phylogeny of New World Myotis (Chiroptera, Vespertilionidae) inferred from mitochondrial and nuclear DNA genes. Mol. Phylogenet. Evol. 43, 32-48.

Sterner, R. T., and G. C. Smith, 2006: Modelling wildlife rabies: transmission, economics, and conservation. Biol. Conserv. 131, 163-179.

Streicker, D. G., A. S. Turmelle, M. J. Vonhof, I. V. Kuzmin, G. F. McCracken, and C. E. Rupprecht, 2010: Host phylogeny constrains cross-species emergence and establishment of rabies virus in bats. Science 329, 676-679.

Streicker, D. G., P. Lemey, A. Velasco-Villa, and C. E. Rupprecht, 2012: Rates of viral evolution are linked to host geography in bat rabies. PLoS Pathog. 8, e1002720. 
Sulkin, S. E., R. Allen, R. Sims, P. H. Krutzsch, and C. Kim, 1960: Studies on the pathogenesis of rabies in insectivorous bats : II. Influence of environmental temperature. J. Exp. Med. 112, 595-617.

Tamura, K., D. Peterson, N. Peterson, G. Stecher, M. Nei, and S. Kumar, 2011: MEGA5: molecular evolutionary genetics analysis using maximum likelihood, evolutionary distance, and maximum parsimony methods. Mol. Biol. Evol. 28, 2731-2739.

Turmelle, A. S., L. C. Allen, F. R. Jackson, T. H. Kunz, C. E. Rupprecht, and G. F. McCracken, 2010: Ecology of rabies virus exposure in colonies of Brazilian free-tailed bats (Tadarida brasiliensis) at natural and man-made roosts in Texas. Vector Borne Zoonotic Dis. 10, 165-175.

Turmelle, A. S., T. H. Kunz, and M. D. Sorenson, 2011: A tale of two genomes: contrasting patterns of phylogeographic structure in a widely distributed bat. Mol. Ecol. 20, 357-375.

Velasco-Villa, A., L. A. Orciari, V. Juarez-Islas, M. GomezSierra, I. Padilla-Medina, A. Flisser, V. Souza, A. Castillo, R. Franka, M. Escalante-Mane, I. Sauri-Gonzalez, and C. E. Rupprecht, 2006: Molecular diversity of rabies viruses associated with bats in Mexico and other countries of the Americas. J. Clin. Microbiol. 44, 1697-1710.

Velasco-Villa, A., S. L. Messenger, L. A. Orciari, M. Niezgoda, J. D. Blanton, C. Fukagawa, and C. E. Rupprecht, 2008a: Identification of new rabies virus variant in Mexican immigrant. Emerg. Infect. Dis. 14, 1906-1908.

Velasco-Villa, A., S. A. Reeder, L. A. Orciari, P. A. Yager, R. Franka, J. D. Blanton, L. Zuckero, P. Hunt, E. H. Oertli, L. E. Robinson, and C. E. Rupprecht, 2008b: Enzootic rabies elimination from dogs and reemergence in wild terrestrial carnivores, United States. Emerg. Infect. Dis. 14, 1849-1854.

Wang, Y., K. J. RowleyB. J. Booth, S. E. Sloan, D. M. Ambrosino, and G. J. Babcock, 2011: G glycoprotein amino acid residues required for human monoclonal antibody RAB1 neutralization are conserved in rabies virus street isolates. Antiviral Res. 91, 187-194.

Wunner, W. H., 2007. Rabies virus. In: Jackson, A. C., and W. H. Wunner (eds), Rabies, 2nd edn. pp. 23-68. Elsevier, Academic Press, London, UK. 